\title{
TCOM \\ Scaling training to support scientists to engage with the public in non-traditional venues
}

\section{Caitlin Weber, Sue Allen and Nalini Nadkarni}

\begin{abstract}
Public engagement with science activities need to be extended beyond traditional learning venues (e.g., museums, schools) to increase public access. Scientists are motivated to carry out this work; however, it is difficult to scale up training to support the implementation of engagement activities in non-traditional venues. Such training would need to be applicable to different engagement contexts, while avoiding a "one size fits all" approach. We describe the guiding principles, challenges, and design choices of a training program in the United States to support scientists in designing and implementing audience-specific engagement activities in a range of non-traditional venues.
\end{abstract}

Keywords

DOI

Introduction
Professionalism, professional development and training in science communication; Public engagement with science and technology; Science communication: theory and models

https://doi.org/10.22323/2.20040802

Submitted: 3rd November 2020

Accepted: 30th March 2021

Published: 17th June 2021

Scientific leaders are calling for scientists to engage with the public [Córdova, 2018; Holt, 2015; Leshner, 2007; Lubchenco, 2005]. Scientists, funders, communication professionals, and communication researchers are responding to these calls. A survey of American Association for the Advancement of Science (AAAS) members documented that $98 \%$ of scientists talk with citizens about science or research [Pew Research Center, 2015]. The National Science Foundation (NSF) includes engagement in its Broader Impacts criterion [National Science Foundation, 2020], and scientists are being trained through scientific societies, academic institutions, and nonprofit organizations [Yuan et al., 2017]. At the same time, communication researchers are studying these activities to inform best practices [American Academy of Arts \& Sciences, 2018; Baram-Tsabari and Lewenstein, 2017; Besley et al., 2016].

Such research has challenged assumptions about effective communication. Historically, many scientists believed that increasing science knowledge would 
change public behaviors and attitudes towards science, the so-called "deficit model" [Besley and Nisbet, 2013; Simis et al., 2016]. However, this approach fails to consider how culture, values, experiences, and identities influence how people process information [American Academy of Arts \& Sciences, 2018; Hart and Nisbet, 2012; Kahan, 2010]. Communication researchers recommend scientists broaden their communication objectives to prioritize forming positive social connections by highlighting shared values, revealing a desire to learn from others, and demonstrating they care about the community [Besley et al., 2018; Dudo and Besley, 2016]. Public engagement with science (PES) is defined by the AAAS as, "intentional, meaningful interactions that provide opportunities for mutual learning between scientists and the public. Mutual learning refers not just to the acquisition of knowledge, but also to increased familiarity with a breadth of perspectives, frames, and worldviews" [American Association for the Advancement of Science, n.d.].

There is also a need to expand the venues where PES occurs. Museums, schools, and other traditional learning venues often serve as institutional hubs for science communication, but their reach is limited. Americans spend less than $5 \%$ of their lives in formal learning venues [Falk and Dierking, 2010]. Even traditional informal learning venues only reach some people as variations in language, culture, education, and financial resources may lead to the systematic exclusion of some communities [Dawson, 2014]. Half of Americans visited a zoo or aquarium in 2018, $30 \%$ visited a natural history museum, and 30\% visited a science center. Americans with more years of formal education and those in higher income brackets were more likely to visit [Besley and Hill, 2020].

One promising strategy to increase access to PES opportunities is to extend engagement beyond traditional venues to settings where science learning is not the primary focus - venues such as cooking classes, public parks, correctional facilities, and senior centers. Training to support scientists engaging in such variable contexts is particularly difficult to scale. Such training needs to be applicable to a range of venues while avoiding a "one size fits all" approach. Training must also prepare scientists to initiate interactions with the public, rather than responding to an invitation. Although people gathered in non-traditional venues may be interested in science, the scientist cannot assume science learning is among their shared motivations for visiting the venue.

Here, we describe the guiding principles, challenges, and scaling of the STEM Ambassador Program (STEMAP), a public engagement training program based in the United States that guides scientists to engage in non-traditional venues. We present three phases towards scaling this work, and outline the key problems that needed to be solved. In Phase I, a single forest ecologist (author Nalini Nadkarni), drew on her research, personal interests, and experiences to engage in several non-traditional venues, including places of worship [Nadkarni, 2007], correctional facilities [Ulrich and Nadkarni, 2009], and fashion shows [Nadkarni and Levey, 2017]. In Phase II, Nadkarni shared her model by providing one-on-one guidance to eight ecologists via the Research Ambassador Program (RAP). In Phase III, an interdisciplinary team formalized RAP's approach to create STEMAP, a semester-long training that has engaged over 70 scientists and 2,580 members of the public since 2016. 
Phase I: exploratory individual work
Nadkarni became interested in PES when she began observing increasing deforestation outside her research sites in the cloud forests of Costa Rica. To bring attention to conservation issues, she began engaging the public via popular science magazines, public television programs, and museums. However, she recognized that many people do not engage through these outlets and became interested in expanding her efforts to new groups.

As a faculty member at The Evergreen State College, an undergraduate institution based on interdisciplinary pedagogy, Nadkarni embraced different ways of knowing and co-taught classes with artists and social scientists. She took a similar interdisciplinary and collaborative approach to PES, developing what would later become the guiding principles of the STEMAP approach.

For example, in 2005, Nadkarni engaged religious communities in discussions about the ecological and spiritual values of trees [Nadkarni, 2007]. Rather than touting the scientific values of trees, Nadkarni drew on religious texts. She searched for the terms "tree" and "forest" in the Bible, the Talmud, the Qur'an, and Hindu and Buddhist texts. She noted the value of trees in those references (e.g., practical values such as food or location markers, aesthetic values such as ornamentation of temples, and metaphorical values such as the Tree of Life) [Nadkarni, 2002]. She approached members and leaders of religious communities with her reflections. Making these contacts herself was initially challenging, as she was not part of a formal religious congregation. Nadkarni was eventually successful in connecting with a Unitarian church after a member of the congregation introduced her to the minister.

Nadkarni attended several services before formally engaging with the congregation. During these "immersion visits", she noted who attended services, what was discussed, and how information was communicated. She talked with church members after the service and learned about their interests and values. Nadkarni then prepared a sermon on trees and spirituality, which she delivered from the pulpit. In the sermon, Nadkarni shared her personal experiences with religion, her forest ecology interests, and what she learned about trees from religious texts. She then invited congregants to share their thoughts and experiences about trees and spirituality.

Other religious leaders welcomed Nadkarni after she had established credibility in the Unitarian Church. She subsequently delivered the sermon in over 40 places of worship. She was invited to participate in tree plantings and discussions on trees and spirituality during meetings in various places of worship.

Nadkarni applied a similar process to work with people who are incarcerated to grow plants for habitat restoration, partner with fashion designers to create clothing inspired by ecological research, advise the Mattel corporation on a line of female scientist "Explorer Barbie" dolls, and carry out several other innovative PES activities [Free, 2020; Nadkarni and Levey, 2017; Nadkarni, 2006; Yoon, 2003]. Although the venues varied widely, each PES project 1) drew on Nadkarni's research, personal interests, and experiences to form authentic connections; 2 ) took place outside traditional learning venues; and 3) prioritized building positive social connections over conveying scientific knowledge. Nadkarni's engagement efforts were commended by the scientific community and funders through a series of national awards and fellowships (2001, 2010, 2011, 2015). 
Given the interest from the public and scientific community, Nadkarni sought to support other scientists in carrying out similar activities. As a faculty member at Evergreen, she had the flexibility to experiment with different PES projects, some of which succeeded (e.g., the trees and spirituality project) and some of which did not (e.g., putting moss displays in elevators). Nadkarni aimed to provide streamlined guidance for scientists who wished to engage in non-traditional venues, but whose professional commitments did not allow as much time as she had enjoyed for experimental PES activities.

Phase II: pilot program
The Research Ambassador Program (RAP) was launched in 2010 to explore scaling up Nadkarni's PES approach by guiding ecologists to engage in non-traditional venues (NSF awards 0956301 and 1141833). RAP was based on the same three principles that inspired Nadkarni's exploratory PES work. First, it leveraged the scientist's research, personal interests, and experiences to identify appropriate venues. Second, RAP carried out activities in non-traditional venues to include people who do not or cannot engage in traditional learning venues. Third, RAP prioritized building positive social connections over communicating science knowledge.

RAP provided comprehensive one-on-one guidance to eight ecologists from eight institutions over four months. Nadkarni met with each ecologist to learn about their interests, presented ecologists with a list of communities or "focal groups" to engage, and matched them to a group. She initiated contact with focal groups on behalf of each ecologist, learned about the group, and advised ecologists on designing engagement activities. Activities included a forest ecologist who prepared a booklet for hospice workers on the inevitability of change in ecosystems and humans, a plant biologist who discussed the plant compounds found in spices at a spice store, and an ornithologist who gave a sermon on birds in the Bible at a church.

Based on post-training interviews by an external evaluator (Cascade Consulting LLC), the RAP ecologists valued the one-on-one guidance from Nadkarni and felt the Program was useful both in improving their communication skills and in thinking creatively about NSF Broader Impacts. They recommended future iterations of the Program include larger workshops and opportunities for one-on-one conversations and feedback from audience members.

RAP demonstrated that ecologists have the desire and capacity to engage in non-traditional venues. However, it lacked a formal training curriculum and so its scalability was limited. Instead, ecologists relied on Nadkarni to identify focal groups to engage, make contact with those groups, and design PES activities. Ecologists had no contact with the focal groups prior to carrying out the PES activity, and were not given skills to independently build social connections with groups. Furthermore, RAP did not include basic communication skills training and so the Program was not suited to ecologists who were not already skilled communicators. Although the Program yielded PES activities in non-traditional venues, it did not prepare ecologists to fulfill the three guiding principles independently. 
The STEM Ambassador Program (STEMAP) was launched in 2016 to scale training while retaining the three guiding principles of Nadkarni's previous work. Whereas RAP was driven largely by Nadkarni's intuition, STEMAP was a collaboration between Nadkarni, an expert in Design Thinking [Goldman, 2017], and leaders in informal science education and the Portal to the Public science communication training program [Selvakumar and Storksdieck, 2013]. An external evaluator (Inverness Research) conducted surveys and interviews with scientists and public participants to assess whether the Program upheld the three guiding principles [Nadkarni et al., 2019].

STEMAP training consists of five modules presented to cohorts of scientists over one semester (Figure 1) [Nadkarni et al., 2019]. Scientists first distill their research, personal interests, and experiences to identify engagement opportunities and focal groups to engage (Module 1, Connect). They then deepen their knowledge of the focal group through meetings with group representatives and visiting focal group venues (Module 2, Immerse). Scientists draw on what was learned about the focal group to design engagement activities (Module 3, Design). They build communication skills to carry out the activities (Module 4, Engage) and engage in the focal group's gathering places. Lastly, scientists reflect on the outcomes and participant feedback (Module 5, Reflect). Here, we describe how each guiding principle was retained and the challenges associated with scaling.

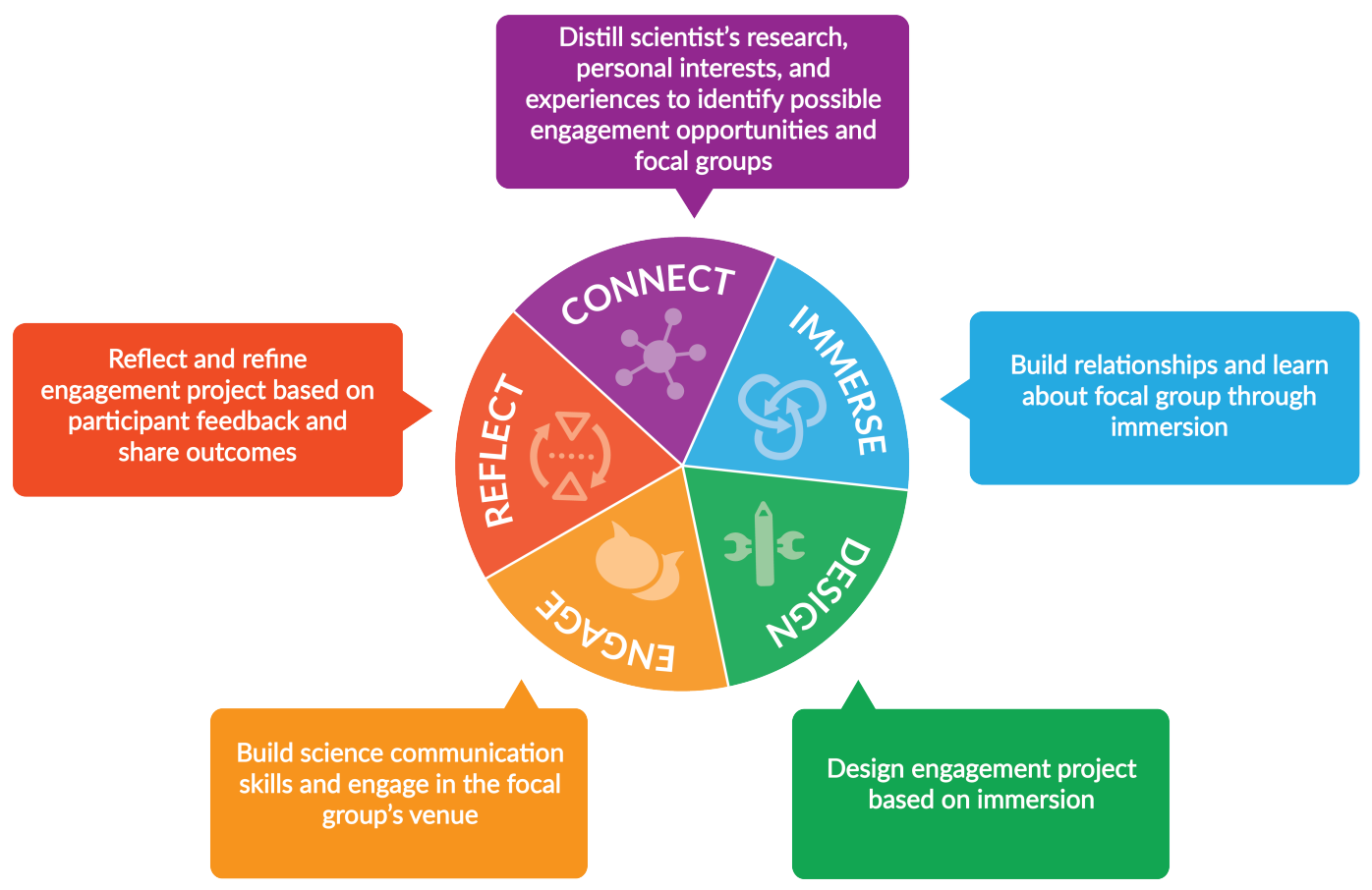

Figure 1. STEMAP engagement process.

\section{Leveraging scientist research, personal interests and experiences for PES}

RAP ecologists relied on Nadkarni's intuition to identify engagement opportunities in non-traditional venues that would be meaningful to both the ecologist and focal group. For greater scaling, we needed to develop steps to guide scientists to better participate in conversations to identify PES opportunities and focal groups. We did 
this by interviewing the scientists about their research, personal interests, and experiences, and prompting them to distill their responses into keywords. We then invited the scientists to review the keywords to brainstorm which focal groups might identify with one or more keyword. Scientists were encouraged to consider focal groups both within and outside their existing networks. For example, an ornithologist who enjoys the outdoors and studies stop over sites used by migratory birds distilled his interview responses into "birds", "migration", "stop over site", "running", and "biking". He identified shared interests with outdoor enthusiasts who might be curious about the birds they see while recreating and also with truck drivers who might identify with the challenges migratory birds face in finding "stop over sites" or rest areas on long journeys (Table 1). Scientists were discouraged from choosing audiences gathered in traditional learning venues, such as school groups or museum visitors, and also from choosing a focal group before considering the broad variety of possible connections.

Table 1. Example scientist keywords and engagement opportunities.

\begin{tabular}{|c|c|c|c|}
\hline Scientist & Research keywords & $\begin{array}{l}\text { Other interests or } \\
\text { experiences }\end{array}$ & Engagement opportunities identified \\
\hline Mathematician & $\begin{array}{l}\text { - Differential } \\
\text { equations } \\
\text { - Math } \\
\text { - Computer } \\
\text { modeling } \\
\text { - Astrocyte } \\
\text { - Neuroscience } \\
\text { - Biology }\end{array}$ & $\begin{array}{l}\text { - Catholic } \\
\text { - Skiing } \\
\text { - Hiking } \\
\text { - Sports }\end{array}$ & $\begin{array}{l}\text { - Discussing math behind } \\
\text { different outdoor sports with } \\
\text { outdoor enthusiasts. } \\
\text { - Sharing the math and } \\
\text { numbers referenced in } \\
\text { religious texts (e.g., } \\
\text { dimensions of Noah's Ark) } \\
\text { with religious communities. }\end{array}$ \\
\hline Chemist & $\begin{aligned} & \text { - } \text { Bacteria } \\
& \text { - Viruses } \\
& \text { - Synthetic } \\
& \text { biology } \\
& \text { - Mirror images } \\
& \text { and chirality } \\
& \text { - Blood-borne } \\
& \text { pathogens } \\
& \text { - Chemistry }\end{aligned}$ & $\begin{aligned} \text { - } & \text { Art/crafting } \\
& \text { (e.g., cardmaking) } \\
\text { - } & \text { Baking } \\
\text { - } & \text { Gardening } \\
\text { - } & \text { Dogs }\end{aligned}$ & $\begin{array}{l}\text { - Discussing mirror images and } \\
\text { chirality with crafters who use } \\
\text { mirror images in their work } \\
\text { (e.g., when making pop-up } \\
\text { cards). } \\
\text { - Engaging tattoo artists in } \\
\text { conversations around mirror } \\
\text { images in art and science and } \\
\text { sharing research on } \\
\text { blood-borne illnesses, which } \\
\text { are of concern to tattoo artists. }\end{array}$ \\
\hline Ornithologist & $\begin{array}{l}\text { - Birds } \\
\text { - Migration } \\
\text { - Climate change } \\
\text { - Conservation } \\
\text { - Tracking } \\
\text { - Stop-over } \\
\text { sites/habitat }\end{array}$ & $\begin{array}{l}\text { - Running } \\
\text { - Skiing } \\
\text { - Biking } \\
\text { - Cooking } \\
\text { - Birding } \\
\text { - Crosswords }\end{array}$ & $\begin{array}{l}\text { - Connecting with people who } \\
\text { travel or migrate (e.g., truck } \\
\text { drivers) and learning from } \\
\text { their experiences with } \\
\text { migration. } \\
\text { - Engaging gardeners or } \\
\text { landscapers in conversations } \\
\text { about bird-friendly landscapes } \\
\text { and how they might create } \\
\text { backyard bird habitat. } \\
\text { - Engaging outdoor enthusiasts } \\
\text { in conversations about the } \\
\text { birds they see while recreating. }\end{array}$ \\
\hline
\end{tabular}

Admittedly, this approach requires scientists to infer the interests of the focal groups they might engage with. For example, the ornithologist predicted that hikers and truck drivers might be interested in engaging, but these groups were not present during the interview to dispel or confirm this. However, the scientist 
cannot extend a compelling invitation to the group without having first thought about how their interests might overlap. Although scientists initiated the first interaction, focal groups would sometimes identify additional connections during the immersion visit or engagement activity. For example, scientists initiated engagement activities with participants on outdoor trips led by a nonprofit organization. The organization's director saw value in these activities, not just for the participants, but also for the guides. The director expanded on the connection by inviting scientists to engage with guides during a pre-season training so guides could share science content on future trips.

\section{Engaging in non-traditional venues}

The STEMAP interview process yielded a range of possible focal groups and engagement venues, based on each scientist's unique research, personal interests, and experiences. With the number of scientists and venues continuing to grow, it would not be feasible for STEMAP to offer a list of focal groups, as RAP had, nor for STEMAP staff to become familiar with all possible venues and focal groups. To address this, we created an Immerse Module, based on Nadkarni's process for learning about religious communities and developed a Design Module to guide scientists to systematically brainstorm focal group-specific engagement activities based on that immersion.

During the Immerse Module, scientists participate in a workshop and review reading materials to prepare to initiate contact with a focal group. In some cases, the group is familiar to the scientist (e.g., a scientist hiker engaging fellow hikers), but we still encourage an immersion so the scientist can learn about the group through the lens of PES. Scientists then visit the focal group's venue and make observations to inform the PES activity design. For example, a biologist seeking to engage a homebrewing club first attended several of the group's meetings to learn about their organization and interests. The Immerse Module provides concrete generalizable strategies to prepare each scientist to learn about a focal group.

We incorporated aspects of the Design Thinking process [Goldman, 2017; McDonagh and Thomas, 2010] into a Design Module to guide scientists to brainstorm engagement activities based on what they learned from the immersion visit. Design Thinking is a teachable process used by designers to create user-centered products and solutions to ill-defined or 'wicked' problems. Designers learn about and empathize with the end-user, reflect on what is learned, define the design need, and brainstorm solutions. During the Design Module, scientists create a guiding statement based on the immersion visit and brainstorm engagement ideas, which are shared with the focal group for feedback. For example, the biologist summarized what he learned about the homebrewing club (e.g. their shared interests, meeting formats, experiences) from his immersion visit and listed his engagement objectives (e.g., highlight shared interest in brewing, convey role of plants in brewing) in a guiding statement. He then worked with STEMAP staff and his peers to brainstorm engagement activities to fulfill the guiding statement. The Design Module offered clear steps for scientists to apply what they learned during the immersion to brainstorm focal group-specific activities. Together, the Immerse and Design modules improved the scalability of STEMAP by eliminating the need for the Program staff to become experts on each 
focal group, reducing scientist reliance on one-on-one support, and providing a process that scientists could repeat with new groups throughout their careers.

Scientists receive training to carry out their engagement activities through the Engage Module, which is based on the Portal to the Public Program [Pacific Science Center, Institute for Learning Innovation, 2018; Selvakumar and Storksdieck, 2013]. This Module covers basic communication skill-building such as addressing jargon and facilitating productive dialogues with participants.

Many STEMAP venues are not truly "public" places that scientists can readily visit (e.g., correctional facilities, senior centers). Setting up appointments to meet focal group representatives, or visit a focal group venue can take several weeks. As a result, the Immerse Module leaves less time for scientists to repeat PES activities or engage with multiple focal groups over the course of the training than if groups and venues were pre-arranged by STEMAP. Additionally, non-traditional venues often do not experience the same level of turnover in visitation as a museum or science center. For example, a scientist engaging in a museum may have access to hundreds of new visitors each week. A hiking club, on the other hand, might have the same ten members who meet each month, which means activities cannot simply be repeated. However, a single engagement activity can still be meaningful and effective at evoking curiosity to learn more. For example, pre- and post-surveys of people who are incarcerated attending science presentations in correctional facilities documented a greater shift in desire to seek more information about science and scientists in participants who attended just one lecture compared to those who attended multiple lectures [Horns et al., 2020]. Small scale projects can also serve as a launch point for larger efforts. Nadkarni's work with religious communities began at one Unitarian Church before expanding to over 40 places of worship. Rather than focusing on increasing the number of PES activities or participants per scientist, we define STEMAP scaling as growing the number of scientists prepared to effectively replicate this approach independently throughout their careers.

\section{Prioritizing positive social connections}

Mutual learning and building social connections are at the core of the AAAS definition of PES quoted above. RAP ecologists were encouraged to build positive social connections with participants, but were not given explicit training for doing so. The scaled STEMAP training explicitly emphasizes PES objectives to form social connections (e.g., highlighting shared values between the scientist and focal group, revealing the scientist's desire to learn from others, showing the scientist cares about the community). Scientists are introduced to the PES approach and objectives during an orientation, and the objectives are revisited in subsequent workshops and included in the design process [Nadkarni et al., 2019]. Scientists aim to form social connections, not only during the engagement activity, but also in the weeks leading up to and following the activity. Scientists indicate their desire to learn from others by articulating what they hope to learn, in addition to what they wish to share, when first contacting a focal group. They then learn from the group during the immersion process. For example, a cancer researcher seeking to engage with electricians first met with a member of this focal group to learn about his work. She drew on what she learned from this meeting to engage electricians in a 
discussion about the "wiring" of the cancer genome and how this compares to the wiring of electrical systems. Her primary objective was not to ensure the electricians knew facts about cancer, but instead to show humility as a scientist and reveal her willingness to consider other ways of knowing. The Reflect Module leads the scientist to review participant feedback in the context of their engagement objectives and consider ways to improve future activities.

Prioritizing social connections can shift the perspectives of both the scientist and the focal group. Because scientists often prioritize conveying scientific information when communicating with the public [Besley and Nisbet, 2013; Simis et al., 2016], focal group members may have experienced and even come to expect this type of one-way communication. A scientist can lay the groundwork for PES by acknowledging the focal group's expertise and stating a desire to learn from the group early on. Mutual learning is not limited to mutual learning of scientific information; focal groups may offer a range of expertise based on their own experiences (e.g., people who are incarcerated help shape engagement activities for incarcerated populations) or expertise in a shared hobby (e.g., outdoor guides teach a mathematician to cross country ski).

STEMAP training is limited to a single semester, and so we do not expect scientists to form deep relationships or launch ongoing programs with a focal group during the training. Likewise, focal groups vary in their desire and capacity to form long-term partnerships with scientists. Scientists are advised to respect the group's limitations and interests while also being transparent about their own limitations. Scientists approach groups with humility and present themselves as participants in a communication training, so it is clear that they are honing their skills. They avoid overpromising large engagement activities, as failure to deliver on these could damage the trust built with the focal group. While scientists are required to carry out just one engagement project as part of their training, many continue participating in PES activities afterwards.

\section{Outcomes of scaling}

We provided STEMAP training to three cohorts of scientists (46 individuals) at the University of Utah from 2016-2018. Cohorts included graduate students (35), faculty (6), and postdocs (5) from 19 fields of study (Table 2).

Training was modified after each cohort, based on scientist and focal group feedback. Feedback was collected via voluntary surveys and interviews administered by a team of researchers and an external evaluator. The team drew on existing evaluation instruments, particularly from the Portal to the Public Program, for evaluating the impact of PES on scientists and public participants. Evaluation activities were granted an exemption from review by an independent review board (Ethical \& Independent Review Services, \#16032) and research activities were reviewed and approved by the Stanford University Institutional Review Board (\#31164).

Scientists were invited to complete a pre- and post-training survey. Surveys were adjusted as the training evolved to evaluate new training resources (see Supplement 1 for 2018 surveys). Pre-surveys were 15-20 questions long. Post-surveys included some of the same questions as the pre-survey and questions about the scientist's overall experience and training resources. Surveys took 15-20 
Table 2. STEMAP scientist fields of study.

\begin{tabular}{|c|c|c|}
\hline College & Field of study & $\begin{array}{l}\text { Number of } \\
\text { scientists }\end{array}$ \\
\hline College of Architecture & City and Metropolitan Planning & 1 \\
\hline \multirow[t]{4}{*}{ College of Engineering } & Biomedical Engineering & 1 \\
\hline & Civil and Environmental Engineering & 1 \\
\hline & Electrical Engineering & 1 \\
\hline & Mechanical Engineering & 1 \\
\hline \multirow{3}{*}{$\begin{array}{l}\text { College of Mines } \\
\text { and Earth Sciences }\end{array}$} & Atmospheric Sciences & 1 \\
\hline & Geology and Geophysics & 7 \\
\hline & Material Science & 1 \\
\hline \multirow[t]{4}{*}{ College of Science } & Chemistry & 1 \\
\hline & Math & 1 \\
\hline & Physics & 2 \\
\hline & School of Biological Sciences & 15 \\
\hline \multirow{2}{*}{$\begin{array}{l}\text { College of Social } \\
\text { and Behavioral Science }\end{array}$} & Anthropology & 3 \\
\hline & Psychology & 2 \\
\hline \multirow[t]{5}{*}{ School of Medicine } & Biochemistry & 1 \\
\hline & Human Genetics & 2 \\
\hline & Huntsman Cancer Institute & 3 \\
\hline & Neurobiology & 1 \\
\hline & Pathology & 1 \\
\hline
\end{tabular}

minutes to complete. Thirty-seven scientists from 2016-2018 completed both the pre-survey and the post-survey.

Scientists in the 2016-2018 cohorts uncovered new engagement opportunities by drawing on their research, personal interests, and experiences. Before completing STEMAP training, $78 \%(n=37)$ of scientists taking the pre-survey felt their ability to engage was limited by a lack of venues or opportunities. This dropped to $27 \%$ $(n=37)$ of scientists who completed the post-survey after the training. Scientists engaged in over 40 non-traditional venues, and created a range of activities based on their interests and experiences and those of the focal group.

Scientists reported that their participation in STEMAP increased their interest in continuing to engage and in reaching new focal groups, suggesting that the supports for initiating contact and learning about a focal group had given them confidence for creating future PES opportunities. Nearly all $(97 \%, n=37)$ scientists who completed the post-survey agreed or strongly agreed with the statement, "The STEM Ambassador program increased my interest in offering science outreach activities to new audiences". Most $(89 \%, n=37)$ agreed or strongly agreed with the statement, "I want to reach out to new audiences as a result of participating in the STEM Ambassador program". Fourteen of fifteen scientists responding to a retrospective survey administered in 2019 indicated that they continued to engage after their participation in STEMAP. In some cases, scientists expanded activities with the same focal group (e.g., a scientist visits multiple senior centers), and in other cases they engaged a new group. 
Overall, scientists were successful in connecting with people who do not or cannot engage with science or scientists through conventional outlets. For example, six secure facilities (four secure youth centers, one county jail, one state prison) hosted scientists; these are settings where participants are physically unable to leave to visit traditional learning venues, so it is important to bring scientists to them, in their living spaces. Members of other focal groups also indicated they had limited opportunities to interact with scientists prior to STEMAP contacting them.

Where feasible, focal group members were invited to provide feedback on their interactions with scientists. Survey instruments were adapted to reflect changes to the training and different engagement contexts (e.g., shorter surveys were used for brief interactions, large print surveys were prepared for senior citizens) (see Supplement 2 for 2018 surveys). The evaluator developed a one-page survey that asked participants about their interest in science, opportunities to interact with scientists, if they learned something from the scientist, and if they felt confident to engage in science activities in the future. Participants could complete these forms in 5-10 minutes. A half-page survey, which took under 5-minutes to complete, was created for situations where it was not feasible to administer the one-page survey. This survey asked participants how interesting the program was, if they wanted to learn more from the scientist, and if they wanted to learn more about the topic discussed. It was not possible to survey participants at every engagement activity due to variations in the activity format (e.g., a survey was not feasible for an activity on a whitewater rafting trip) and human subject protections (e.g., we did not have permission to survey certain youth populations). The reported sample sizes $(n)$ indicates the total number of people who responded to a particular survey question.

Of the surveyed focal group members, $85 \%$ ( $n=210$ total survey respondents) agreed or strongly agreed that the scientist was open to and encouraging of the focal group's questions and ideas. Nearly all $(96 \%, n=207$ total survey respondents) agreed or strongly agreed that the scientist did a good job communicating and $88 \%(\mathrm{n}=101$ total survey respondents) indicated that they would like to learn more about the scientist's work. One focal group representative noted in an interview with the evaluator, "I was so impressed with the grad students. They were asking the right questions, and they had the right kind of attitude about working with our kids. They had a high level of awareness of what sort of situation they are coming into and what some of the needs were".

Reflections and future work
We increased the capacity of Nadkarni's individual work and RAP's one-on-one guidance by drawing on other training models to create a semester-long scientist training program to support engagement in non-traditional venues. We scaled training by giving scientists explicit steps to broaden their sense of possible connections to new focal groups and design engagement activities specific to the group. This gave scientists significant autonomy in choosing, connecting with, and successfully engaging in non-traditional venues.

We offer three recommendations on scaling PES training more generally. First, identify the most fundamental guiding principles before scaling up. Several tradeoffs were needed to scale from Nadkarni's individual work, to RAP, to STEMAP, including removing or modifying Design Thinking, Portal to the Public, 
and RAP activities or terminology that did not align with the STEMAP principles. Early identification of principles that the team felt must be retained allowed us to make informed design decisions with the greatest degree of mutual understanding.

Second, determine which aspects of the program will be scaled up. We focused on scaling the number of scientists trained to replicate the STEMAP process throughout their careers, rather than scaling up the number of people scientists reach during STEMAP training.

Third, we suggest timing the training exercises so that the scientists have the opportunity to apply their new skills as soon as possible. Initially, STEMAP was presented in one or two full-day workshops before scientists had contacted a focal group. As a result, scientists required extensive one-on-one guidance (similar to the RAP model) following the workshops to recall and apply the material to their PES activities. Splitting the training into multiple workshops allowed us to present each module when it was most relevant to the scientists. For example, rather than practice the design process with hypothetical scenarios, scientists received design training after completing their immersion visits and applied the training directly to their engagement activities. This reduced staff time for one-on-one meetings and encouraged scientists to put STEMAP training into practice. It also increased scientists' motivation to learn because they could see the immediate relevance of the materials.

We continue to scale STEMAP's capacity to reach other institutions and more scientists. STEMAP is currently based in the United States, though scientists and communicators in other countries have expressed interest in the Program. We have outlined ways to scale PES within the United States, but approaches may vary in different locations and contexts. We are exploring four ways to scale and sustain this Program further: 1) implement a mentorship model to prepare STEMAP alumni to support current trainees to further reduce reliance on one-on-one staff support and allow the Program to support more scientists; 2) pilot online and "train-the-trainer" formats to export STEMAP to other institutions; 3) refine evaluation and self-reflection instruments to better support scientists in reviewing and responding to participant feedback; and 4) collaborate with professionals in the business (impact investment) arena to identify pathways for sustainability.

Acknowledgments

The STEM Ambassador Program was funded by the National Science Foundation (EHR 1514494 and 1906408). We thank Becky Carroll and Inverness Research for external evaluation, Megan Young for program coordination, Dennis Schatz and Shelley Goldman for guidance in integrating Portal to the Public and Design Thinking into the training, and the Sorenson Impact Center for guidance in scaling activities. We acknowledge participating scientists and community partners.

References

American Academy of Arts \& Sciences (2018). Perceptions of science in America. A report from the Public Face of Science Initiative. Cambridge, MA, U.S.A. URL: https://www . amacad.org/multimedia/pdfs/publications/researchpap ersmonographs/PFoS-Perceptions/PFoS-Perceptions-Science-America.pdf.

American Association for the Advancement of Science (n.d.). Public engagement. URL: https: //www . aaas .org/focus-areas/public-engagement. 
Baram-Tsabari, A. and Lewenstein, B. V. (2017). 'Science communication training: what are we trying to teach?' International Journal of Science Education, Part B 7 (3), pp. 285-300. https : //doi.org/10.1080/21548455.2017.1303756.

Besley, J. C., Dudo, A. and Yuan, S. (2018). 'Scientists' views about communication objectives'. Public Understanding of Science 27 (6), pp. 708-730. https://doi.org/10.1177/0963662517728478.

Besley, J. C., Dudo, A., Yuan, S. and Abi Ghannam, N. (2016). 'Qualitative interviews with science communication trainers about communication objectives and goals'. Science Communication 38 (3), pp. 356-381. https://doi.org/10.1177/1075547016645640.

Besley, J. C. and Hill, D. (2020). 'Science and technology: public attitudes, knowledge, and interest'. National Science Foundation, National Science Board. Science E Engineering Indicators. URL: https://ncses .nsf .gov/pubs/nsb20207/.

Besley, J. C. and Nisbet, M. (2013). 'How scientists view the public, the media and the political process'. Public Understanding of Science 22 (6), pp. 644-659. https://doi.org/10.1177/0963662511418743.

Córdova, F. A. (2018). 'Importance of engagement and openness with the public and policymakers'. In: American Association for the Advancement of Science Annual Meeting (Austin, TX, U.S.A. 16th February 2018). URL: https : //www .ns f.gov/news/speeches/cordova/18/fc180216_aaas_annual.jsp.

Dawson, E. (2014). "'Not designed for us": how science museums and science centers socially exclude low-income, minority ethnic groups'. Science Education 98 (6), pp. 981-1008. https://doi.org/10.1002/sce.21133.

Dudo, A. and Besley, J. C. (2016). 'Scientists' prioritization of communication objectives for public engagement'. PLoS ONE 11 (2), e0148867. https://doi.org/10.1371/journal . pone.0148867.

Falk, J. H. and Dierking, L. D. (2010). 'The 95 percent solution'. American Scientist 98 (6), pp. 486-493. https://doi.org/10.1511/2010.87.486.

Free, C. (17th January 2020). 'She started climbing trees as a kid. Then this ecologist helped create scientist Barbie'. The Washington Post. URL: https://www. washing tonpost.com/lifestyle/2020/01/17/she-started-climbing-trees-kid-the n-this-ecologist-helped-create-scientist-barbie/.

Goldman, S. (2017). 'Design thinking'. In: The SAGE encyclopedia of out-of-school learning. Ed. by K. Peppler. Vol. 1. London, U.K.: SAGE Publications, pp. 210-212. https://doi .org/10.4135/9781483385198.n84.

Hart, P. S. and Nisbet, E. C. (2012). 'Boomerang effects in science communication: how motivated reasoning and identity cutes amplify opinion polarization about climate mitigation policies'. Communication Research 39 (6), pp. 701-723. https://doi.org/10.1177/0093650211416646.

Holt, R. D. (2015). 'Why science? Why AAAS?' Science 347 (6224), p. 807. https://doi.org/10.1126/science.aaa9126.

Horns, J. J., Nadkarni, N. and Anholt, A. (2020). 'How repeated exposure to informal science education affects content knowledge of and perspectives on science among incarcerated adults'. PLoS ONE 15 (5), e0233083. https://doi.org/10.1371/journal.pone.0233083.

Kahan, D. M. (2010). 'Fixing the communications failure'. Nature 463 (7279), pp. 296-297. https://doi.org/10.1038/463296a.

Leshner, A. I. (2007). ‘Outreach training needed'. Science 315 (5809), p. 161. https://doi.org/10.1126/science.1138712. 
Lubchenco, J. (11th November 2005). 'Science's communication gap'. The New York Times. URL: https://www . nytimes . com/2005/11/11/opinion/sciences-commun ication-gap.html.

McDonagh, D. and Thomas, J. (2010). 'Rethinking design thinking: empathy supporting innovation'. Australasian Medical Journal 3 (8), pp. 458-464. https://doi.org/10.4066/AMJ .2010.391.

Nadkarni, N. (2002). 'Trees and spirituality: an exploration'. Northwest Dharma News 15 (October/November), pp. 9-10, 13. URL: https://nalininadkarni.com /wp-content/uploads/2020/11/spirituality_Dharma-News-Nadkarni.pdf.

- (2006). 'The Moss-in-Prison project: disseminating science beyond academia'. Frontiers in Ecology and the Environment 4 (8), pp. 442-443. https: //doi.org/10.1890/1540-9295 (2006) 4 [442:TMPDSB] 2.0.CO;2.

- (2007). 'Ecological outreach to faith-based communities'. Frontiers in Ecology and the Environment 5 (6), pp. 332-333. https://doi.org/10.1890/1540-9295(2007)5[332:EOTFC]2.0.C0;2.

Nadkarni, N. and Levey, D. (2017). 'Ecology on the runway: engaging the public in unexpected places'. Bulletin of the Ecological Society of America 98 (2), pp. 103-109. https://doi.org/10.1002/bes2.1302.

Nadkarni, N., Weber, C. Q., Goldman, S. V., Schatz, D. L., Allen, S. and Menlove, R. (2019). 'Beyond the deficit model: the ambassador approach to public engagement'. BioScience 69 (4), pp. 305-313. https://doi.org/10.1093/biosci/biz018.

National Science Foundation (2020). Proposal \& Award Policies \& Procedures Guide. URL: https://www.nsf.gov/publications/pub_summ.j.sp?ods_key=papp.

Pacific Science Center, Institute for Learning Innovation (2018). Portal to the Public Implementation Manual.

URL: https://popnet.instituteforlearninginnovation.org/about/.

Pew Research Center (2015). How scientists engage the public.

URL: http://assets . pewresearch .org/wp-content/uploads/sites/14/2015 /02/PI_PublicEngagementbyScientists_021515.pdf.

Selvakumar, M. and Storksdieck, M. (2013). 'Portal to the public: museum educators collaborating with scientists to engage museum visitors with current science'. Curator: the Museum Journal 56 (1), pp. 69-78. https://doi.org/10.1111/cura.12007.

Simis, M. J., Madden, H., Cacciatore, M. A. and Yeo, S. K. (2016). 'The lure of rationality: why does the deficit model persist in science communication?' Public Understanding of Science 25 (4), pp. 400-414. https://doi.org/10.1177/0963662516629749.

Ulrich, C. and Nadkarni, N. (2009). 'Sustainability research and practices in enforced residential institutions: collaborations of ecologists and prisoners'. Environment, Development and Sustainability 11 (4), pp. 815-832. https://doi.org/10.1007/s10668-008-9145-4.

Yoon, C. K. (23rd September 2003). 'Making science rock, roll and swing from the treetops'. The New York Times. URL: https://www. nytimes . com/2003/09/23/sci ence/making-science-rock-roll-and-swing-from-the-treetops.html.

Yuan, S., Oshita, T., AbiGhannam, N., Dudo, A., Besley, J. C. and Koh, H. E. (2017). 'Two-way communication between scientists and the public: a view from science communication trainers in North America'. International Journal of Science Education, Part B 7 (4), pp. 341-355.

https://doi.org/10.1080/21548455.2017.1350789. 

Ambassador Program at the University of Utah (www.stemap.org) where she provides training to support scientists in engaging with the public in non-traditional learning venues. E-mail: caitlin.weber@utah.edu.

Sue Allen (Ph.D., University of California at Berkeley) is a Senior Research Scientist at the Maine Mathematics and Science Alliance. Her research focuses on supporting and assessing STEM learning in a variety of out-of-school settings, as well as professional learning for educators in such settings. E-mail: sallen@mmsa.org.

Nalini Nadkarni (Ph.D., University of Washington) is a Professor in the School of Biological Sciences at the University of Utah. Her research is both on forest canopy ecology and on ways to promote informal science learning between scientists and public groups in non-traditional science education venues.

E-mail: Nalini.nadkarni@utah.edu.

How to cite

\section{Supplementary material}

Weber, C., Allen, S. and Nadkarni, N. (2021). 'Scaling training to support scientists to engage with the public in non-traditional venues'. JCOM 20 (04), N02. https://doi.org/10.22323/2.20040802.

Available at https://doi.org/10.22323/2.20040802.

\section{Supplement 1 .}

- STEM Ambassador 2018 scientist pre-training survey

- STEM Ambassador 2018 scientist post-training survey

\section{Supplement 2.}

- STEM Ambassador 2018 participant feedback form

- STEM Ambassador 2018 participant feedback survey

- STEM Ambassador 2018 participant feedback survey (short form) 